\title{
New species of Orthocentrinae (Hymenoptera: Ichneumonidae) from Finland
}

\author{
Andrei E. Humala
}

Humala, A. E. 2008: New species of Orthocentrinae (Hymenoptera: Ichneumonidae) from Finland. — Entomol. Fennica 19: 94-104.

Five new species of ichneumonids of the subfamily Orthocentrinae $s$. $l$. were discovered in Finnish collections. A new genus is proposed for one new species from Southern Finland, Fennomacrus koponeni gen. et sp. n. Its relationships and systematic position are briefly discussed. Four other new species, Plectiscidea aquilonia sp. n., P. fuscifemur sp. n., P. helleni sp. n. and Eusterinx (Holomeristus) fennoscandica sp. n., from Fennoscandia are also described. The hitherto unknown female of Helictes fabularis Rossem is described as well.

A. E. Humala, Forest Research Institute, Karelian Centre of the Russian Academy of Sciences. Pushkinskaya St. 11, Petrozavodsk 185910, Russia; E-mail: humala@krc.karelia.ru

Received 14 June 2006, accepted 30 July 2007

\section{Introduction}

The subfamily Microleptinae sensu Townes (Hymenoptera: Ichneumonidae) was established as an independent taxon roughly equivalent to its modern usage by A. Förster under the name Plectiscoidae (Förster 1869). He described the majority of recent genera and a lot of species, revealing their significant morphological diversity (Förster 1869, 1871). Some ichneumonids similar to plectiscines belonging to other subfamilies, e.g. Ateleute, Polyaulon, Symphylus (=Acrodactyla), Adelognathus, were included by him in this group as well. On the other hand, many genera without a closed areolet in the fore wing, which are included nowadays in Orthocentrinae, were described by Förster in other groups of ichneumonids. C. G. Thomson considered plectiscines among other Tryphonidae close to orthocentrines, and divided them into 4 sections (Thomson 1888). He synonymised some of Förster's genera and changed their status to subgenera for some others.
H. Townes, based on the fact that the type species of the type genus (Plectiscus impurator Gravenhorst, 1829) belongs to Orthocentrinae, proposed a new name for this group - Microleptinae (Townes 1958). He placed together with plectiscines several genera of unclear relationships, admitting that this subfamily was a "wastebasket group" (Townes 1971). Although some genera, such as Oxytorus, Tatogaster, Acaenitellus and Microleptes, were later excluded from the group (and in this connection the subfamily name has changed 3 times during the last 20 years), up to now a uniform and generally accepted classification is missing, and the subfamily still remains insufficiently known, because of its high morphological diversity and confusing taxonomy.

After several genera were removed, the remaining ones were treated as the subfamily Helictinae (Gupta 1987, Gauld 1991, Dasch 1992). Resulting from the works of Wahl (1986, 1990), they were united with the orthocentrines within Orthocentrinae s. $l$. (Yu \& Horstmann 
1997, Wahl \& Gauld 1998), while Cylloceria and Allomacrus were removed from other "helictines" into the subfamily Cylloceriinae. The Palaearctic fauna of these two segregated genera was recently revised (Humala 2002), and two species, Cylloceria tenuicornis Humala, 2002 and Allomacrus subtilis Humala, 2002, were described from Finland and Russia. The third genus Rossemia ( $=$ Sweaterella) included in this group was described from the Karelian Republic and the Far East (Humala 1997, Wahl \& Gauld 1998).

According to the Catalogue of World Ichneumonidae (Yu \& Horstmann 1997) the Orthocentrinae $s$. $l$. comprises 31 recent genera, with moderate numbers of species, though the structure and composition of the subfamily are still far from stable. Since that time the genus Kentrotryphon was synonymised under Allomacrus (Schwarz 2004), genus Epitropus under Adelognathus, Pantomima under Acrodactyla, Fetialis under Aclastus (Broad 2004) and the genus Cressonia was transferred to Diacritinae (Wahl \& Gauld 1998).

All species for which the biology is known are larval koinobiont endoparasitoids of Diptera Nematocera, primarily fungus gnats (Sciaroidea). Orthocentrines comprise a common and conspicuous part of the ichneumonid fauna, especially in north and temperate regions, where the group is particularly species-rich and abundant, but up to now this subfamily is one of the least known within Ichneumonidae.

\section{Materials and methods}

For the present research the collections of Orthocentrinae $s$. $l$. stored at the Zoological Museum, Finnish Museum of Natural History of Helsinki University, including the collection of Wolter Hellén (ZMHU), and Department of Applied Biology of the Helsinki University (DABHU) - now part of ZMHU - were studied. Additional material collected during entomological investigations in the Biosphere Nature reserve "Northern Karelia" in 1994-1999 and in some adjacent territories, stored at the Karelian Research Centre in Petrozavodsk (KRC) and at the Zoological Institute of Russian Academy of Sciences, St. Petersburg (ZIN), were also used.
Some collections of the Zoological Museum of Uppsala University (UUZM) have been revised as well. Morphological terminology mainly follows Gauld (1991). Finnish collecting localities are provided with coordinates using $27^{\circ} \mathrm{E}$ grid, biogeographical provinces of East Fennoscandia are given according to Heikinheimo and Raatikainen (1971).

\section{Results and discussion}

\subsection{Genus Fennomacrus gen. n.}

Diagnosis. Fennomacrus can be distinguished from all other ichneumonid genera by the following combination of features: the wide and flat clypeus (Fig. 1b); mandibles not twisted, with subequal teeth; weak notauli; absence of sternauli; first sternite not fused with tergite, with spiracles before mid-length of segment; comparatively short, straight ovipositor; slender legs; presence of areolet; fore wing vein $2 m-c u$ with two bullae; unbroken reclivous nervellus; distinct sculpture of head and mesosoma. In the structure of the first metasomal segment the new genus is close to the representatives of tribe Cylloceriini Wahl, 1990 (Humala 2003, 2007). Fennomacrus differs from Allomacrus in the weak notauli and straight ovipositor; from Entypoma by the weak notauli, straight mandibles, slenderer legs, especially femora, straight ovipositor; from Proeliator and Plectiscidea by the first metasomal segment with tergite and sternite not fused, presence of glymmae on the first tergite, distinct granulate sculpture on head and mesosoma.

Fennomacrus is represented by a single known species. The habitus of the genus is illustrated in Fig. 1a.

To my mind, the genus Allomacrus is much closer to Apoclima and Entypoma than to Cylloceria (Humala 2003), and D. Wahl's arguments for segregation of these two genera (Wahl 1986, 1990) seems not to be convincing, which was confirmed for instance by the synonymy of Allomacrus and Kentrotryphon (Schwarz 2004). So this group should be expanded by including other genera, based on the structure of the first segment of the metasoma. According to Broad (2004, pers. com.), Hyperacmus has a close rela- 


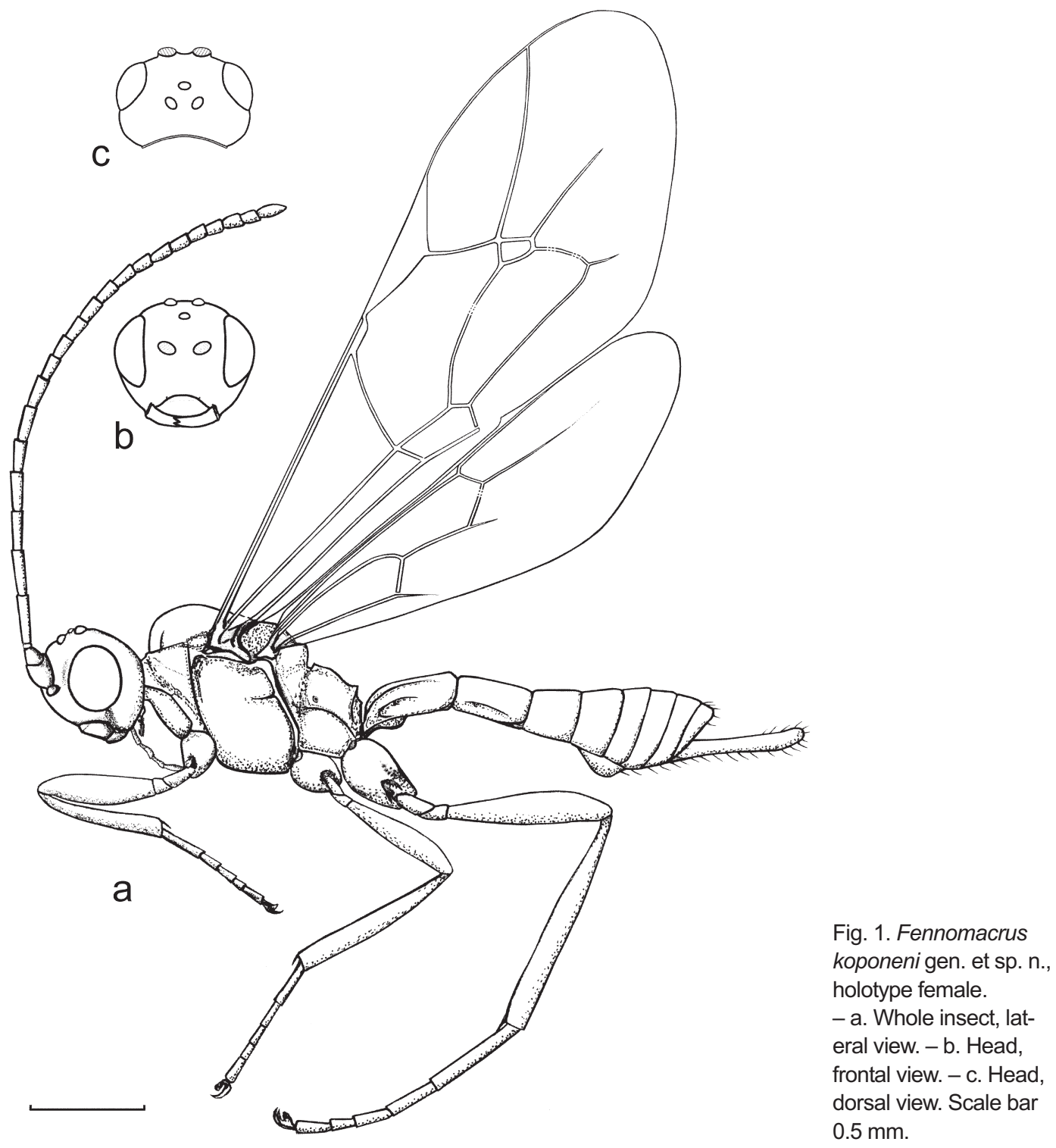

tionship with Orthocentrinae + Cylloceriinae and should not be separated from this group. Indirectly this was confirmed by Šedivý and Ševčík (2003), who reared H. crassicornis Gravenhorst from the fungus gnat Sciophila varia (Winnertz), inhabiting the fruit body of Hydnum repandum L.: Fr. (Cantharellales, Hydnaceae). As a result the new genus is placed together with genera Cylloceria, Hyperacmus, Allomacrus, Rossemia, Apoclima and Entypoma, forming the tribe Cylloceriini Wahl, 1990 within subfamily Orthocentrinae.
Etymology. The name is combined from Fenno - Fennia and macrus - from related genera Allomacrus and Stenomacrus.

\subsubsection{Fennomacrus koponeni sp. n. (Fig. 1)}

Type material. Holotype ${ }_{+}$, Finland, Sa: Ristiina 6826: 502; 4.VII.1980 (M. Koponen leg.) DABHU.

Female (holotype). Body length $2.9 \mathrm{~mm}$; fore wing $3.0 \mathrm{~mm}$; antenna slender, 21 flagellar segments; first flagellar segment $5.0 \times$ as long as 
wide; second flagellar segment $3.6 \times$ as long as wide. Head width $1.1 \times$ height; face width $1.72 \times$ height, $0.57 \times$ head width, matt, punctate, lateral margins parallel; malar space $1.2 \times$ basal width of mandible, with strip of rougher, granulate sculpture between eye and mandible, subocular sulcus absent; mandibles not twisted, teeth subequal; clypeus small and wide, width $2.4 \times$ height (Fig. 1b), slightly convex at base, remainder flattened to apex, transversely weakly convex; anterior tentorial pits small; frons matt; ocular-ocellar distance $(O O L)$ about $1.6 \times$ post-ocellar distance $(P O L), 1.9 \times$ greatest diameter of lateral ocellus; gena well developed, strongly convex, matt, width $3.0 \times$ greatest diameter of lateral ocellus (Fig. 1c); occiput slightly concave, occipital carina complete.

Mesosoma length $1.65 \times$ height, evenly matt except polished on speculum; short epomia present; mesoscutum punctate, notaulus slightly developed anteriorly, obsolete; epicnemial carina complete; sternaulus absent; propodeum coriaceous, carinae complete except lacking costulae and anterior portions of median and lateral longitudinal carinae; propodeal spiracles small. Nervulus nearly interstitial, almost opposite basal vein; subdiscoideus arising at basal 0.7 of postnervulus; areolet large, petiolate; second recurrent vein $2 m-c u$ with two bullae; nervellus reclivous, not intercepted, discoidella lacking. Legs slender; hind femur length $5.2 \times$ height; hind basitarsus $0.41 \times$ length of hind tibia.

First metasomal segment $1.65 \times$ as long as wide apically, granulate, sternite not fused with tergite, reaching 0.36 of segment length, spiracles 0.4 of segment length; median dorsal carinae weak; dorsolateral carinae present; glymmae present; postpetiole length $0.87 \times$ width; second metasomal segment $0.85 \times$ as long as wide apically, granulate; laterotergites separated by a crease; remaining tergites nearly polished, slightly depressed at apex; ovipositor short and straight, somewhat compressed, its sheath rather wide, $0.53 \times$ length of hind tibia.

Colouration. Fuscous, dusky-rufous on mandibles and legs. Dusky-tawny on palpi, clypeus, tegulae and wing bases. Wings hyaline.

Male. Unknown.

Biology. Not known.

Etymology. I am pleased to name this species after Martti Koponen, who collected the only known specimen of the genus.

\subsection{Genus Plectiscidea Viereck, 1914}

Unfortunately the existing key to females of Palaearctic Plectiscidea species (Rossem 1991) is almost of no practical use, as very few characters (mainly the ratio of length of first flagellar segment to its apical width, ratio of length of first metasomal segment to its apical width and ratio of ovipositor length to fore wing length) were used in the key, and it is not enough for reliable species division and recognition. Moreover this key, including newly described species, is not illustrated.

\subsubsection{Plectiscidea aquilonia sp. $n$. (Figs $2 a-b$ )}

Diagnosis. Using van Rossem's key to the genus Plectiscidea (Rossem 1991), this species keys to P. nemorensis Rossem, resembling it in its short ovipositor and in the shape of the first flagellar segment, but differs in having distinct notaulus with weak, short, vertical carina basally on inner side, absence of areolet in fore wing, slender hind femur, more slender first metasomal segment, fuscous clypeus and tergites $2-3$.

The new species should be inserted in the van Rossem's key as follows:

3. Ovipositor short, $0.09-0.10$ of length of front wing, basal flagellomeres with more or less distinct medial notch, thus giving impression of two short inflated segments.

- Ovipositor not shorter than 0.14 of length of front wing.

4. Areolet closed; notauli not developed. Hind femur not so slender. Postanellus long, 6.0 times its apical width. First metasomal segment 2.3 times as long as its apical width. Clypeus, apical part of tergite 2 and tergite 3 medially light brown. Fore wing 3.0-4.1 mm.

nemorensis Rossem

- Areolet open (vein 3rs- $m$ absent); notauli evident, with weak short vertical carina basally from its inner side. Hind femur slender, 7.3 times its height. Postanellus 5.4 times its api- 

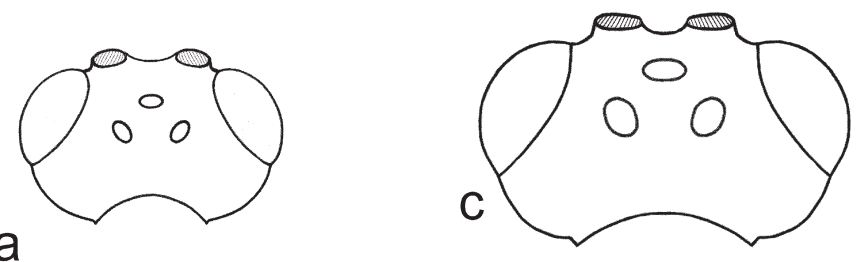

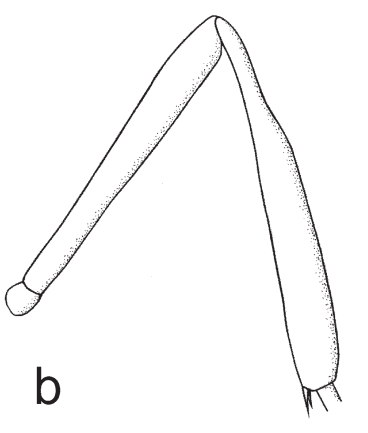

b

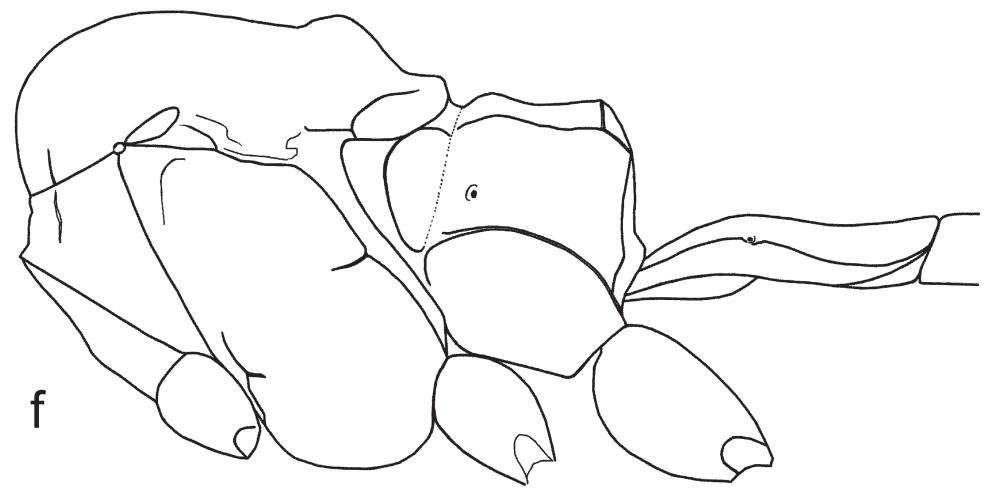

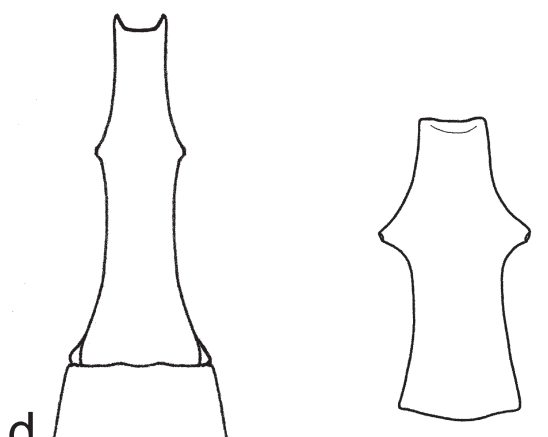

e
Fig. 2. Body parts of Plectiscidea. - a. P. aquilonia sp. n., holotype female. Head, dorsal view. - b. P. aquilonia sp. n., holotype female. Hind femur and tibia. - c. P. fuscifemur sp. n., holotype female. Head, dorsal view. - d. $P$. fuscifemur sp. n., holotype female. Basal metasomal segments, dorsal view.- e. P. hellenisp. n., holotype male. First metasomal segment, dorsal view. $-\mathrm{f}$. P. helleni sp. n., holotype male. Mesosoma, lateral view. Scale bars $0.5 \mathrm{~mm}$. cal width. First metasomal segment 2.6 times as long as its apical width. Clypeus and tergites fuscous. Fore wing $3.0 \mathrm{~mm}$.

aquilonia sp. n.

A vertical carina on the inner side of the notaulus occurs infrequently in a few orthocentrine genera (e.g. Plectiscidea, Symplecis, etc.), though as a rule it is not so well developed as in Aniseres species.

Type material. Holotype $q$ Russia, Khabarovsk Terr., Udyl' lake 9.IX.1970 (D. Kasparyan leg.) ZIN; 5 o 9 paratypes: Khabarovsk Terr., Udyl' lake 10.IX.1970 (D. Kasparyan leg.), Sakhalin, Aniva 11.VII.1981, 13.VII.1981 (S. Belokobylskii leg.) ZIN, Karelia Kon: Nature reserve Kivach 16-19.VIII.1991 (Malaise trap, A. Humala leg.) KRC; Finland, $A b$ : Turku, Ruissalo 6712: 234, 18.IX.1981 (M. Koponen leg.) DABHU.

Female (holotype). Body length $2.9 \mathrm{~mm}$. Fore wing $3.0 \mathrm{~mm}$. Antennae with 16 flagellar segments, first flagellar segment $5.4 \times$ as long as wide, basal segments seeming to be subdivided by medial notch. Face width $0.49 \times$ head width, lateral margins subparallel. Clypeus convex, truncated apically, anterior tentorial pits small. 
Malar space wide, $2.3 \times$ width of mandible, $0.42 \times$ face width; lacking subocular sulcus or band of coriaceous sculpture between eye and mandible. Mandible slender, lower tooth slightly shorter than upper tooth; ocular-ocellar length $(O O L)$ about $1.3 \times$ greatest diameter of lateral ocellus, $1.25 \times$ postocellar length $(P O L)$. Gena convex, width $3.3 \times$ greatest diameter of lateral ocellus; occipital carina complete (Fig. 2a).

Mesosoma $1.49 \times$ as long as high. Epomia well developed, not reaching upper margin of pronotum. Notaulus developed on anterior end of mesoscutum, with weak short vertical carina basally from its inner side. Epicnemial carina complete. Scutellum slightly convex, lateral carinae to near apex; sternaulus short; propodeum weakly developed, carinae complete except lacking anterior transverse carina, propodeal spiracle small. Areolet not closed; second recurrent vein $2 m-c u$ with two bullae; nervulus opposite basal vein; nervellus not intercepted, vertical, discoidella undeveloped. Legs slender, hind coxa polished, hind femur $7.3 \times$ as long as high, hind tibia constricted in basal third, the rest somewhat inflated (Fig. 2b); hind basitarsus $0.40 \times$ length of hind tibia. Propodeum, legs and first metasomal segment covered with long erect hairs.

First metasomal segment coriaceous, $2.6 \times$ as long as wide apically, dorsal and dorsolateral carinae developed in basal 0.3 of segment, its sternite covering basal 0.5 , spiracles at 0.4 of segment length; glymma lacking, second tergite $0.75 \times$ as long as wide apically, polished; remaining tergites polished. Ovipositor very short, $0.32 \times$ hind tibia, about $0.1 \times$ fore wing length (in paratype ovipositor hardly projecting beyond depressed apex of metasoma, its length $0.25 \times$ hind tibia).

Colouration. Fuscous, palpi, mandibles and legs brownish-yellow; face, clypeus, scapi, tegulae, hind coxae and tarsi brownish. Wings hyaline, pterostigma light-brown. There is no significant variation in the examined specimens.

Male. Unknown.

\subsubsection{Plectiscidea fuscifemur $s p$. $n$. (Figs $2 c-d)$}

Diagnosis. The new species can be distinguished from other representatives of the genus by the long and slender first metasomal segment, com- paratively short, slightly upcurved ovipositor and dark hind femora.

Type material. Holotype 9 , Finland, $N$ : Helsinki, Kannelmäki 6682: 382, 16.IX.1978 (M. Koponen leg.); 2 + 9 paratypes, $A b$ : Vihti, Siikajärvi (val.), 24.IX-1.X.1971 (A. Petramaa leg.), $N$ : Nurmijärvi, Murhamäki 6710: 381, 23.IX. 1993 (M. Koponen leg.) DABHU; paratype $\hat{\jmath}$, Russian Karelia Kon: 5 km S Medvezh'jegorsk 7.VI.2000 (A. Humala leg.) ZIN.

Female (holotype). Body length 4.6 (4.5-4.7) $\mathrm{mm}$. Fore wing $4.5(4.4-4.5) \mathrm{mm}$. Antennae long, 19 (20 in paratype) flagellar segments; first flagellar segment $6.9 \times$ as long as wide, second $6.0 \times$ as long as wide. Clypeus slightly convex, clypeal foveae small. Face width $0.48 \times$ head width, lateral margins parallel. Malar space $0.33 \times$ face width, about $1.45 \times$ basal width of mandible; lacking subocular sulcus between eye and mandible, but strip of coriaceous sculpture present. Mandible slender, tapered, lower tooth slightly shorter than upper tooth; ocular-ocellar length $(O O L)$ about $1.2 \times$ post-ocellar length $(P O L)$, $1.4 \times$ greatest diameter of lateral ocellus; gena convex, width $2.9 \times$ greatest diameter of lateral ocellus, head behind eyes strongly narrowed (Fig. 2c); occipital carina complete.

Mesosoma $1.61 \times$ as long as high. Epomia strong, reaching upper side of pronotum. Notaulus shallow, weakly developed on anterior end of mesoscutum. Sternaulus short, but well developed. Epicnemial carina not interrupted, not reaching anterior margin of mesopleuron. Scutellum slightly convex, lateral carinae to near apex. Propodeum coriaceous, carinae complete except lacking anterior transverse carina, propodeal spiracles small. Areolet petiolate, comparatively large; nervulus opposite basal vein; second recurrent vein $2 m-c u$ with two bullae; nervellus indistinctly intercepted below the middle, discoidella not pigmented. Legs slender, hind coxa coriaceous; hind femur $6.7 \times$ as long as high; hind basitarsus $0.46 \times$ length of hind tibia.

First metasomal segment long and slender, $2.6 \times$ as long as wide apically, coriaceous (Fig. 2d); carinae undeveloped, glymmae lacking; sternite at 0.53 , spiracles at 0.36 of segment length; second tergite as long as wide apically, basal part of segment coriaceous medially, thyridia absent; laterotergite not separated by a crease, 
spiracles of tergites 2 and 3 on laterotergites; remaining tergites polished. Metasoma slightly compressed at apex; ovipositor short, 0.44× length of hind tibia, $0.13 \times$ fore wing, apical part slightly upcurved.

Colouration. Fuscous, mandibles, palpi, scapi ventrally, tegulae, fore and middle legs, hind coxae apically, trochanters of hind legs, apical third of second tergite and third tergite yellow. Antennae dark brown. Base of hind coxae, hind femora, apical half of hind tibiae and tarsi brown. Wings hyaline. There is no significant variation in the examined specimens.

Male. Body length $4.3 \mathrm{~mm}$. Fore wing 4.1 $\mathrm{mm}$; antennae in only known specimen broken after third flagellomere; first flagellar segment $5.7 \times$ as long as wide, second flagellar segment as long as first. Clypeus convex. Face width $0.45 \times$ head width, lateral margins subparallel. Malar space $0.31 \times$ face width, about $1.5 \times$ basal width of mandible; $O O L$ about $1.2 \times P O L, 1.2 \times$ greatest diameter of lateral ocellus; gena convex, width $2.7 \times$ greatest diameter of lateral ocellus. Mesosoma $1.48 \times$ as long as high. Legs slender, hind femur $6.8 \times$ as long as high; hind basitarsus $0.41 \times$ length of hind tibia. First metasomal segment long and slender, $2.8 \times$ as long as wide apically, coriaceous; sternite at 0.46 , spiracles at 0.38 of segment length; second tergite $1.2 \times$ as long as wide apically, basal part of segment coriaceous medially; remaining tergites polished. Other characters and colouration as in female.

\subsubsection{Plectiscidea helleni sp. n. (Figs 2e-f).}

Diagnosis. The species is recognizable by its unusually cubic propodeum and the strongly protruding spiracles of the first metasomal segment.

Type material. Holotype đ̂, Finland, Le: Enontekiö, Kilpisjärvi, Siilastupa 11.VII.1950 (W. Hellén leg.) ZMHU.

Male (holotype). Body length $4.2 \mathrm{~mm}$. Fore wing $4.0 \mathrm{~mm}$. Scapus large, ovoid, its truncation with rounded incision. Antennae consist of 21 comparatively stout flagellar segments, first flagellar segment $3.8 \times$ as long as wide, second flagellar segment length $3.6 \times$ width, elevated tyloids on segments 5-7 of flagellum. Head polished with sparse hairs. Face width $0.56 \times$ head width; gena convex, width $2.5 \times$ greatest diameter of lateral ocellus; occipital carina complete; ocular-ocellar length $(O O L)$ as long as post-ocellar length $(P O L), 1.4 \times$ greatest diameter of lateral ocellus. Clypeus convex; lacking subocular sulcus between eye and mandible, but a strip of coriaceous sculpture present. Malar space about $1.3 \times$ basal width of mandible; tip of mandibles invisible because of inconvenient mounting.

Mesosoma $1.47 \times$ as long as high. Epomia strong, reaching upper side of pronotum. Scutellum with lateral carinae not reaching apex. Notaulus present. Central part of mesoscutum polished, covered with sparse hairs, middle surfaces of propleuron and mesopleuron polished, hairless. Sternaulus short; propodeum of almost cubic shape (Fig. 2f), carinae complete except lacking anterior transverse carina, propodeal spiracle small. Areolet present, second recurrent vein $2 m$-cu with two bullae; nervulus opposite basal vein; nervellus indistinctly intercepted below the middle, discoidella not pigmented. Legs of moderate size; hind femur length $6.1 \times$ height.

First segment of metasoma $2.6 \times$ as long as wide apically, its sternite at 0.41 , spiracles at 0.36 its length; glymmae lacking; weak carinae developed in basal third of segment. Postpetiole somewhat striated and compressed dorso-ventrally. Spiracles of first metasomal segment strongly protruding, the width of segment at spiracles $1.2 \times$ its apical width (Fig. 2e). Second tergite polished, thyridia small, remaining tergites polished. Propodeum and metasoma covered with long, sub-erect hairs.

Colouration. Fuscous, clypeus, palpi, mandibles, tegulae, legs including coxae, apical third of tergite 2 and basal half of tergite 3 yellow. Antennae yellowish, fuscous dorsally. Wings hyaline, pterostigma light brown.

Female. Unknown.

Etymology. This species is named in honour of the collector, Wolter Hellén - a famous Finnish specialist in Ichneumonidae. 


\subsection{Genus Eusterinx Förster, 1869}

Subgenus Holomeristus Förster, 1869

\subsubsection{Eusterinx (Holomeristus) \\ fennoscandica sp. n. (Fig. 3)}

Diagnosis. From the closely allied E. (Holomeristus) aquilonigena Rossem the new species differs in its inflated genae and long notauli meeting in the centre of the mesoscutum. From Proeliator proprius Rossem it differs in strongly twisted mandibles, the shape of clypeus, the number of tyloids and the presence of costulae.

Type material. Holotype $\pi$ Finland, $N$ : Nurmijärvi, Röykkä hospital 6712: 370, 6.IX. 1986 (M. Koponen leg.) DABHU; paratype $\hat{\sigma}$ with the same data; paratype $q N$ : Orimattila, 6754: 419, 21.IX.1980 (M. Koponen leg.) DABHU; paratype + Sweden, Upl: Uppsala, Starbo 7.X.1979 (M. Idar leg.) UUZM.

Male (holotype). Body length 3.0 (3.1) mm. Fore wing 3.1 (3.2) mm. Scapus large, ovoid. Flagellum consist of 23 (24) segments, first flagellar segment $4.5 \times$ as long as wide, second flagellar segment length $3.8 \times$ width, tyloids on flagellum segments 6-8. Head polished with sparse hairs. Face width $0.49 \times$ head width; head distinctly widened behind the eyes level (Fig. 3b), genae strongly convex, inflated, occipital carina complete; ocular-ocellar length $(O O L) 2.0 \times$ postocellar length $(P O L), 1.7 \times$ greatest diameter of lateral ocellus. Clypeus large, $2.1 \times$ as wide as long, convex basally, remaining part slightly concave, its apical margin transparent, covered with long hairs; subocular strip of coriaceous sculpture between eye and mandible present. Malar space narrow, about $0.3 \times$ basal width of mandible, $0.20 \times$ face width. Mandibles wide basally, strongly twisted inwards, lower tooth small, invisible in frontal view; upper edge sharply delimited from frontal surface of mandibles, lower edge bordered with transparent lamella (Fig. 3a).

Mesosoma $1.50 \times$ as long as high. Epomia present, reaching upper side of pronotum. Notauli well developed, meeting in the centre of mesoscutum. Scutellar lateral carinae absent. Epicnemial carina complete; sternaulus short; propodeum with all carinae developed, area petiolaris comparatively small, narrow; area superomedia

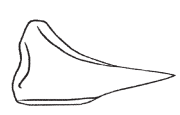

a

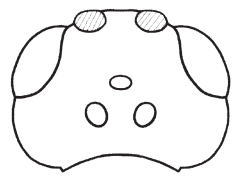

b

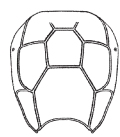

C
Fig. 3. Eusterinx (Holomeristus) fennoscandica sp. n., holotype male. - a. Right mandible. - b. Head, dorsal view. - c. Propodeum, dorsal view. Scale bars $0.1 \mathrm{~mm}$ (a) and $0.5 \mathrm{~mm}(\mathrm{~b}, \mathrm{c})$.

parallel-sided (Fig. 3c). Fore wing with large areolet, second recurrent vein $2 m-c u$ with two bullae; nervulus inclivous, slightly distal of basal vein; nervellus reclivous, not intercepted. Legs of moderate size; hind femur length $5.7 \times$ height; hind basitarsus $0.37 \times$ length of hind tibia.

First segment of metasoma $2.5 \times$ as long as wide apically, sternite at 0.6 , spiracles at 0.45 its length; sternite and tergite fused, glymmae lacking; median and lateral longitudinal carinae developed; postpetiole somewhat striated. Second metasomal segment length $0.87 \times$ as long as apical width, thyridia undeveloped, tergite subpolished; remaining tergites polished.

Colouration. Fuscous, head almost black. Clypeus, palpi, mandibles, base of antennae, malar space, lower gena, propleuron, tegulae, legs including coxae yellow. Face and the rest of antennae brownish. Wings hyaline, pterostigma light brown.

Female. Body length $3.1 \mathrm{~mm}$., fore wing 3.1 $\mathrm{mm}$. Flagellum consist of 23 segments, first flagellar segment $4.8 \times$ as long as wide. Ovipositor straight, its length $0.95 \times$ hind tibia length or $0.25 \times$ fore wing. Other characters and colouration as in male.

Tentative key to the Palaearctic species of subgenus Holomeristus Förster:

1. Posterior transverse carinae of propodeum forming weak apophyses. Malar space long, about $0.4 \times$ face width. Hind femur inflated, $5.5 \times$ as long as high. [Clypeus convex. Flagellum of $q$ with 18 segments, $1^{\text {st }}$ flagellomere $3.3 \times$ as long as apical width; $\precsim$ 
tyloids on flagellomeres 6-7. Tergite 2 of metasoma coriaceous. Ovipositor upcurved, $0.23-0.25 \times$ fore wing length. Body length 4.1 $\mathrm{mm}$., fore wing 3.3-3.8 $\mathrm{mm}$ ].

refractaria Rossem

- Propodeum without apophyses. Malar space shorter, $0.18-0.30 \times$ face width. Hind femur not inflated

2. Notauli not reaching centre of mesoscutum. 3

- Notauli well developed, meeting in centre of mesoscutum. Malar space $0.20-0.25 \times$ face width.

3. Malar space short, $0.18 \times$ face width. Flagellum of $\odot$ with $20-21$ segments, $1^{\text {st }}$ flagellomere slender, $4.5 \times$ as long as apical width, of with 21-24 segments, tyloids on flagellomeres 6-9(10)(11). Inner orbits subparallel. Area superomedia not longer than width, costulae more or less developed, apical area long. Tergite 1 coriaceous, $2.3 \times$ as long as apical width; tergite 2 of metasoma basally with longitudinal striae, apical part polished. Ovipositor $0.14-0.19 \times$ fore wing length. Fore wing $3.1 \mathrm{~mm}$.

aquilonigena Rossem

- Malar space $0.28 \times$ face width on the level of antennae, $1.4 \times$ basal width of mandible. Flagellum with 20 segments, $1^{\text {st }}$ flagellomere $4.6 \times$ as long as apical width, tyloids absent. Inner orbits weakly converging downwards. Area superomedia elongate, costulae weak. Tergite 1 polished, $2.7 \times$ as long as apical width; tergite 2 with fine longitudinal striae. Body length $3.4 \mathrm{~mm}$., fore wing $3.0 \mathrm{~mm}$. simplicornis Humala ( 9 unknown)

4. Head distinctly widened behind the eyes (Fig. $3 b)$, genae strongly convex, inflated. Clypeus large, $2.1 \times$ as wide as long, convex basally, remaining part slightly concave, apical margin transparent. Mandibles wide basally, strongly twisted inwards; lower edge bordered with transparent lamella (Fig. 3a). Malar space narrow, $0.20 \times$ face width. flagellum consists of 23-24 segments, tyloids on flagellomeres 6-8. Mesopleuron without longitudinal striae. Area superomedia parallel-sided (Fig. 3c). Tergite 2 of metasoma subpolished. Pronotum and metasomal tergites fuscous. Legs, including coxae yellow. Ovipositor straight, $0.95 \times$ hind tibia length or $0.25 \times$ fore wing. Body length 3.0 $3.1 \mathrm{~mm}$., fore wing $3.1-3.2 \mathrm{~mm}$.

fennoscandica sp. $\mathrm{n}$.

- Head not so widened behind the eyes. Clypeus not so large, mostly flattened. Mandibles not so wide basally, without transparent lamella on lower edge. Malar space 0.23 $0.25 \times$ face width. Flagellum 9 consists of 16 segments, $1^{\text {st }}$ flagellomere 3.0-5.0 times longer its apical diameter, apical flagellomere clavate; ô 18-19(20) segments, tyloids on flagellomeres 6-7(8)(9). Rear of lower mesopleuron with narrow strip of longitudinal striae. Area superomedia of propodeum elongate, narrowed posteriorly, costulae well developed. Metasomal segments 2 and most of 3 coriaceous, longitudinally striate. Ovipositor distinctly upcurved, $0.20-0.29$ of fore wing length. Pronotum and metasomal segments $2-3$, at least apically, often yellow, hind coxae and femora fuscous. Body length 3.9$4.1 \mathrm{~mm}$, fore wing $3.1-3.8 \mathrm{~mm}$.

tenuicincta Förster

\subsection{Genus Helictes Haliday, 1837}

\subsubsection{Helictes fabularis Rossem, 1987 (Fig. 4)}

Material. 7 우 were found together with $\widehat{\partial}$ from Russia, Karelia, Kon: Kivach Nature Reserve, birch and mixed forests, 6-9.IX.1991, 1316.IX.1991, 20-24.IX.1991, 27-30.IX.1991, 29.X.1990, 11-15.X.1991 (Malaise traps, A. Humala leg.) KRC.

Female. Body length $4.5-5.8 \mathrm{~mm}$, fore wing 4.5-5.8 $\mathrm{mm}$; antennae slightly longer than in male, 25-28 flagellomeres: first flagellar segment $7.0 \times$ as long as wide, second flagellar segment length $3.6 \times$ width; middle segments nearly $2.0 \mathrm{x}$, subapical flagellomeres $1.5 \times$ as long as wide; scapi inflated, obliquely truncated forming angle of about $45^{\circ}$; head width $1.05 \times$ height; face convex, width $0.60 \times$ head width, clypeus convex, apical margin truncate; anterior tentorial pits of moderate size, open; malar space long, $2.5 \times$ basal width of mandible, with granular subocular strip; mandibles strongly tapered, twisted inwards, upper tooth longer than lower tooth; ocelli of moderate size, $O O L$ as long as $0.8 \times P O L, P O L 2.2 \times$ as 


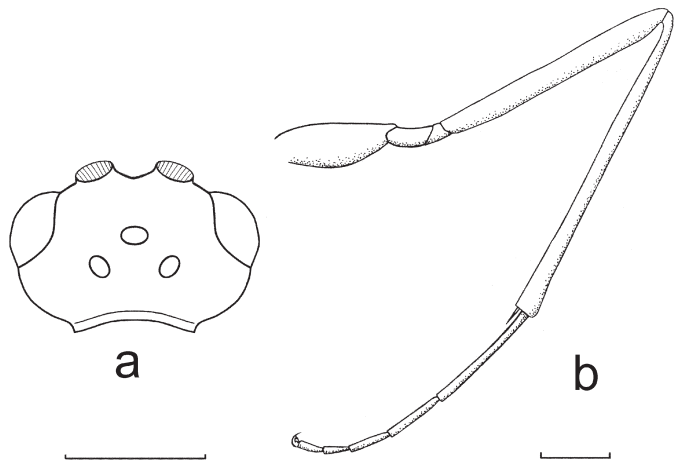

Fig. 4. Helictes fabularis Rossem, female. - a. Head, dorsal view. - b. Hind leg, lateral view. Scale bar 0.5 $\mathrm{mm}$.

long as diameter of lateral ocellus. Occipital carina well developed; eyes comparatively small, convex; genae strongly convex, width $3.3 \times$ greatest diameter of lateral ocellus (Fig. 4a).

Mesosoma length $1.6 \times$ height; epomia present; mesoscutum finely granulate, subpolished; notauli sharp, well developed; epicnemial carina not interrupted; sternauli lacking; propodeum granulate, posterior transverse carina well developed as a crest, with two small flattened apophyses; spiracles small. Legs long and slender, hind coxae elongate, subpolished; hind femur length $10.0 \times$ height; hind basitarsus $0.36 \times$ length of hind tibia (Fig. 4b). Fore wing without areolet; vein $2 r s-m$ short and somewhat widened; second recurrent vein $2 m-c u$ with two bullae. Nervulus weak distally of basal vein. Nervellus intercepted below the middle, discoidella weak, unpigmented.

First metasomal segment $2.3 \times$ as long as wide apically, petiole somewhat arched; sternite and tergite fused, no glymma present, spiracle and apex of sternite at 0.45 of segment length. Second metasomal segment length $1.05 \times$ as long as apical width. Hypopygium well developed. Ovipositor hardly surpasses apex of metasoma, sheath length equal to second segment of hind tarsus, tip of sheath slightly widened and truncate.

Colouration. Fuscous, palpi and tegulae ivory; mandibles and legs except yellowish front coxae rufous; flagellum, clypeus, upper hind corners of pronotum, apical margins of tergite 2 and basal half of tergite 3 yellowish-brown. Wings hyaline, veins and pterostigma light brown.
Acknowledgements. The author is grateful to the Nordic Council of Ministers and Centre for International Mobility (CIMO) who supported this research on Finnish collections in 1996 and in 1998; to Anders Albrecht (ZMHU), Martti Koponen (DABHU) and Mattias Forshage (UUZM) for access to collections; to Reijo Jussila for subsequent access to his collection; to the staff of the Zoological Museum of Helsinki University and Department of Applied Biology of the same University. Martti Koponen is thanked for supplying with exact information on collecting localities in Finland. I am also much indebted to Gavin Broad for reviewing the manuscript, valuable comments and improving the English.

\section{References}

Broad, G. R. 2004: Generic synonymies affecting the Orthocentrinae (Hymenoptera: Ichneumonidae), with notes on the composition of the subfamily. - Entomologist's Monthly Magazine 140: 297-299.

Dasch, C. E. 1992: The Ichneumon-flies of America North of Mexico: Part 12. Subfamilies Microleptinae, Helictinae, Cylloceriinae and Oxytorinae (Hymenoptera: Ichneumonidae). - Mem. Amer. Entomol. Inst. 52: $1-470$.

Förster, A. 1869: Synopsis der Familien und Gattungen der Ichneumonen. - Verhandlungen des Naturhistorischen Vereins der Preussischen Rheinlande und Westfalens. 25: 135-221.

Förster, A. 1871: Übersicht der Gattungen und Arten der Familie der Plectiscoiden. — Verhandlungen des Naturhistorischen Vereins der Preussischen Rheinlande und Westfalens. 28: 71-123.

Gauld, I. 1991: The Ichneumonidae of Costa Rica, 1. Mem. Amer. Entomol. Inst. 47: 1-589.

Gupta, V. K. 1987: The Ichneumonidae of the Indo-Australian area (Hymenoptera). A synoptic catalogue of the taxa described through 1985 together with bibliography, 1960-1985. - Mem. Amer. Entomol. Inst. 41(2): 1-1210.

Heikinheimo, O. \& Raatikainen, M. 1971: Paikan ilmoittaminen Suomesta talletetuissa biologisissa aineistoissa. - Ann. Entomol. Fenn. 37(1a): 1-30.

Humala, A. E. 1997: Oxytorinae from Karelia new to Russia and description of a new genus and two new species (Hymenoptera: Ichneumonidae). — Zoosystematica Rossica. 5(2): 297-300.

Humala, A. E. 2002: A review of parasitic wasps of the genera Cylloceria Schiødte, 1838 and Allomacrus Förster, 1868 (Hymenoptera, Ichneumonidae) of the fauna of Russia. - Entomol. Rev. 82: 301-313. [Translated from Entomologicheskoe Obozrenie 81(2): 370-385].

Humala, A. E. 2003: The ichneumonid wasps in the fauna of Russia and adjacent countries: Microleptinae and Oxytorinae (Hymenoptera: Ichneumonidae). — Nauka, Moscow. 175 pp. [In Russian.]

Humala, A. E. 2007: 27. Subfamily Orthocentrinae. - In: 
Lelej, A. S. (ed.), Key to the insects of Russian Far East. Vol. IV. Neuropteroidea, Mecoptera, Hymenoptera. Pt 5: 680-718. Dal'nauka, Vladivostok. 1052 pp. [In Russian.]

Rossem, G. van 1991: New Oxytorinae from Siberia, with revised keys to Plectiscidea Viereck and Eusterinx Foerster s.l. (Hymenoptera, Ichneumonidae) - Zool. Med. Leiden. 1991. Deel 65, N 3. P.25-38.

Schwarz, M. 2004: Schlupfwespen (Insecta, Hymenoptera, Ichneumonidae) in den Hochlagen der Hohen Tauern (Österreich). Teil 2: Bemerkungen zu ausgewähIten Arten einschließlich der Beschreibung neuer Arten. - Linzer biol. Beitr. 35: 1097-1118.

Šedivý, J. \& Ševčík, J. 2003: Ichneumonid (Hymenoptera: Ichneumonidae) parasitoids of fungus gnats (Diptera: Mycetophilidae): rearing records from the Czech Republic. - Studia Dipterologica 10(1): 153-158.

Thomson, C.G. 1888: Försök till gruppering af slägtet Plectiscus (Grav.). - Opuscula Entomologica 12(38): 1266-1318.
Townes, H. K. 1958: The application of the name Plectiscus (Hymenoptera, Ichneumonidae). - Proc. Entomol. Soc. Wash. 60: 221.

Townes, H. 1971: The Genera of Ichneumonidae. Pt 4. Mem. Amer. Entomol. Inst. 17: 1-372.

Wahl, D. B. 1986: Larval structures of oxytorines and their significance for the higher classification of some Ichneumonidae (Hymenoptera). - Syst. Entomol. 11: 117-127.

Wahl, D. B. 1990: A review of the mature larvae of Diplazontinae, with notes on larvae of Acaenitinae and Orthocentrinae and proposal of two new subfamilies (Insecta: Hymenoptera, Ichneumonidae). — J. Nat. Hist. 24: 27-52.

Wahl, D. B. \& Gauld, I. D. 1998: The cladistics and higher classification of the Pimpliformes (Hymenoptera: Ichneumonidae). - Syst. Entomol. 23: 265-298.

Yu, D. S. \& Horstmann, K. 1997: Catalogue of world Ichneumonidae (Hymenoptera). — Mem. Amer. Entomol. Inst. 58: 1-1558. 